\title{
Pesquisa Agropecuária Pernambucana: Passado e Futuro
}

Foi com muita honra e satisfação que assumi a responsabilidade de ser editor-chefe da Pesquisa Agropecuária Pernambucana (PAP). Os últimos seis meses foram de intensa dedicação à revista, e os frutos deste esforço conjunto - do Comitê Editorial, da Diretoria de Pesquisa e da Presidência do Instituto Agronômico de Pernambuco (IPA) - serão apresentados neste volume (17) e nos próximos que virão.

Imerso no resgate das publicações do então Instituto de Pesquisas Agronômicas, tive a grata satisfação de encontrar em sua biblioteca a primeira publicação técnico-científica seriada do instituto. A primeira edição dos "Archivos do Instituto de Pesquisas Agronomicas" (Figura 1) foi publicada em março de 1938 apresentando "trabalhos originaes sobre assumptos de interesse da região em que está localisado, mostrando assim que se vem desincumbindo da tarefa para que foi criado" palavras do então diretor do instituto, o Dr. João de Vasconcellos Sobrinho.

Em outro trecho das "Informações Ligeiras", Vasconcellos Sobrinho descreve a região da qual nosso estado, Pernambuco, faz parte e finaliza com a descrição

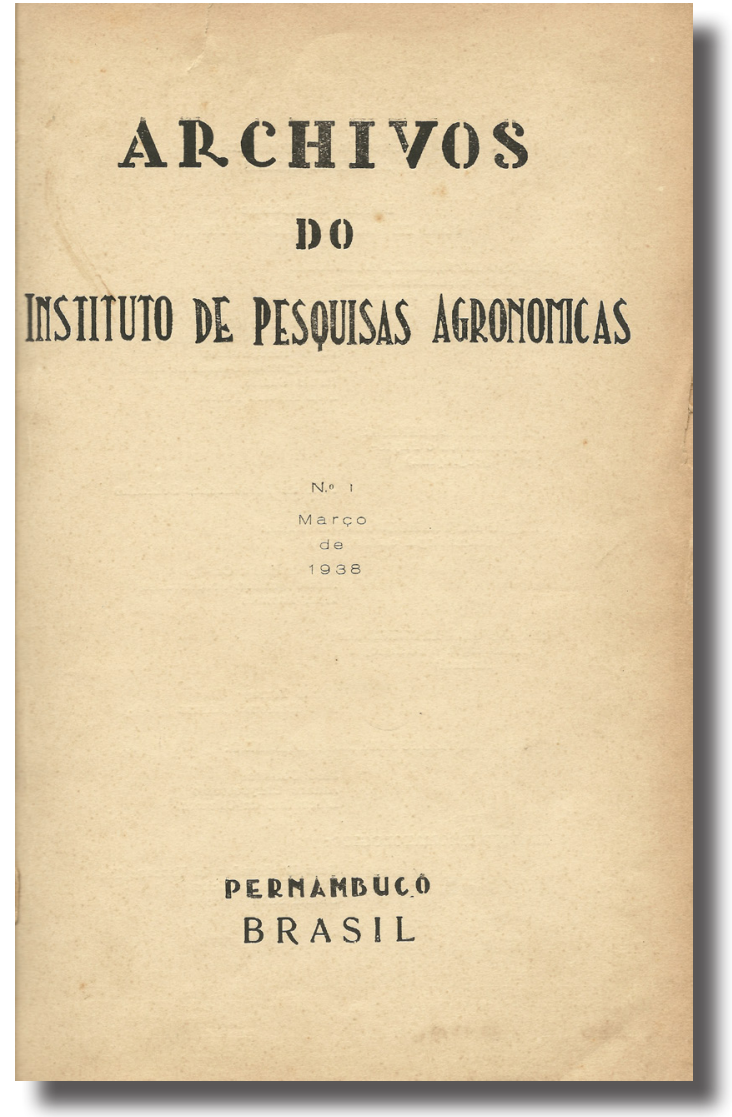

Figura 1. Capa do primeiro volume da publicação "Archivos do Instituto de Pesquisas Agronomicas" publicado em 1938. Fonte: Acervo da Biblioteca do Instituto Agronômico de Pernambuco (IPA). do conteúdo encontrado no primeiro artigo publicado, em latim, pelo próprio Vasconcellos:

“... passaremos em revista primeiro o solo e o clima, depois a flóra e a fauna e, passando além das formações naturaes, abordaremos as condições do meio em relação ao homem, falando assim do homem primitivo dessa região, tudo perfunctoriamente, apenas com o fim de que os leitores dos trabalhos publicados nos - Archivos do Instituto Agronomico de Pernambuco - se identifiquem, quanto possivel, com o meio em que são realisados".

Outros três volumes dos "Archivos do Instituto de Pesquisas Agronomicas" circularam entre 1939 e 1946, com o total de 38 trabalhos. Alguns desses são verdadeiros tratados sobre a economia agrária, história da evolução da agricultura, evolução da agricultura brasileira, e a silvicultura no Nordeste.

Em 1957, inicia-se uma "Nova Série de Publicações", numa sequência de sete números. Essa série foi sucedida, em 1961, pelo "Boletim Técnico do Instituto de Pesquisas Agronômicas", monografias seriadas, cuja última publicação foi a de número 76, que circulou em dezembro de 1976.

Caminhando na cronologia das publicações do IPA, em dezembro de 1977 teve início a vida da PAP, como é mais conhecida hoje, que assim comemora, com este volume, 35 anos de circulação. No volume 1, número 1, de dezembro de 1977 (Figura 2), o então Diretor-presidente do IPA, Paulo Ernani Siqueira de Araújo, escreve:

"Dentro do plano geral de divulgação das atividades técnico-científicas da Empresa insere-se a publicação deste periódico - Pesquisa Agropecuária Pernambucana - PAP, que temos a satisfação de apresentá-lo para o conhecimento das autoridades, entidades, cientistas, pesquisadores, professores e estudiosos interessados. Os informes técnico-científicos aqui aparecerão com o intuito de colocar, mais objetivamente, ao alcance da comunidade técnico-científica, os avanços tecnológicos gerados em todo o território estadual". 
É com o mesmo sentimento de outrora, de divulgar as atividades técnico-científicas oriundas de pesquisas de interesse agropecuário, que a revista PAP se renova, buscando ampliar sua penetração e circulação. Para tanto, foi reestruturada em seu formato, com uma nova diagramação e uma nova capa. A partir de agora, os artigos enviados para a PAP serão exclusivamente submetidos pelo site da revista, o que reduzirá o tempo de tramitação, desde a submissão até a publicação online. Para este fim, será adotado o sistema "ahead of print", que permite a divulgação antecipada dos artigos aceitos antes da publicação final do número impresso.

Entre as novidades, destaca-se ainda a atribuição do Digital Object Identifier, o DOI, para cada artigo aceito. O DOI, número único que identifica um documento digital, já é padrão nos periódicos internacionais e está se tornando padrão também nos periódicos científicos brasileiros, o que facilita a busca e a indexação dos artigos.

Com isso, se terá uma revista mais dinâmica, com tempo de avaliação baixo, com uma publicação rápida e de qualidade. Somente desta forma se pode corresponder à confiança dos leitores, autores e revisores que fazem parte da PAP.

Além dos volumes futuros, pretende-se resgatar as publicações anteriores da "Pesquisa Agropecuária Pernambucana", do "Boletim Técnico do Instituto de Pesquisas Agronômicas" e dos "Archivos do Instituto de Pesquisas Agronomicas", que estarão disponíveis no site da revista e poderão ser consultados livremente pela comunidade. Esta será uma forma singela de homenagear todos os que contribuíram com as publicações do IPA, divulgando a ciência a serviço da sociedade, particularmente do homem rural.

A PAP é bastante singular em relação a outros periódicos, uma vez que assume uma posição de interface entre a pesquisa agropecuária e a

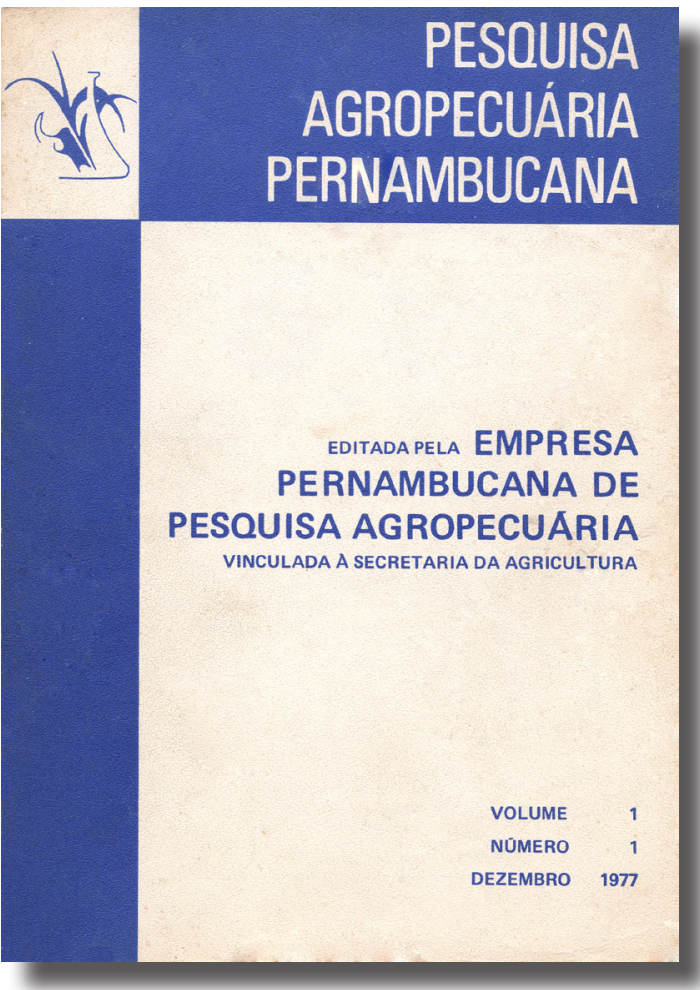

Figura 2. Capa do primeiro volume da revista "Pesquisa Agropecuária Pernambucana" publicada em 1977. Fonte: Acervo da Biblioteca do Instituto Agronômico de Pernambuco (IPA).

extensão rural, publicando artigos científicos relevantes para ambas as áreas, bem como aqueles advindos da integração entre a academia e o campo.

Como editor-chefe, me empenharei sempre para alcançar o melhor e espero contar com o apoio da comunidade técnicocientífica para atingir o objetivo maior, que é colaborar para o desenvolvimento da agricultura de Pernambuco, do Nordeste e do Brasil.

Bem-vindos à nova PAP.

Henrique Castelletti Editor-chefe 